\title{
Conhecimentos em contato na formação pré-serviço
}

\author{
Simone Reis \\ Telma Nunes Gimenez \\ Denise Ismênia Bossa Grassano Ortenzi \\ Elaine Fernandes Mateus \\ Universidade Estadual de Londrina
}

\section{Abstract}

A case study analysing the socialization of a student-teacher of English language is presented. Based on data stemming from a questionnaire, an autobiographical report, a class observation report, two tape-recorded supervision sessions, and one semi-structured interview, the case shows the use of a social strategy by the studentteacher as a way to survive the practicum supervision provided at the university. By identifying the student-teacher's beliefs, we found that because biography is central to the socialization process, it is necessary to reconsider other ways to achieve the goals of the established teacher education curriculum. 
T a literatura sobre socialização do professor, isto é, sobre como pessoas aprendem a ser professores (STATON \& HUNT, 1992), encontramos conceitos que ajudam a compreender as reações de alunos-professores ao conhecimento que lhes é proposto na supervisão de estágio de inglês. Alguns conceitos se referem a estratégias sociais (LACEY, 1977, apud ZEICHNER \& TABACHNICK, 1985) adotadas por alunos-professores diante de imposições institucionais. Essas estratégias se distinguem em termos de comprometimento com valores e conformidade de comportamento. Lacey identifica três tipos de estratégias usadas nos contextos institucionais. Para este relato de estudo de caso, interessam-nos apenas duas. Uma delas, chamada ajuste internalizado, mostra o futuro professor aceitando totalmente a definição de uma situação dada por uma autoridade da instituição. Isso seria um indicativo de que a pessoa se torna o tipo de pessoa que a situação requer e a socialização se dá tanto pela conformidade comportamental quanto pela adesão a valores. Quando um indivíduo aceita as condições colocadas por uma situação, mantendo reserva pessoal ao fazê-lo, sua reação revela aquiescência estratégica. Isto quer dizer que a pessoa não age de acordo com suas crenças e que sua conformidade é uma reação adaptada à situação, sem os valores correspondentes que o comportamento presume.

O objetivo deste artigo é descrever e analisar a socialização de uma aluna-professora, Maria ${ }^{1}$, a partir de seu ponto de vista. Queremos não somente mostrar a'natureza individual desse processo, mas também, enquanto formadoras de professores, registrar nosso pensamento sobre esse papel e sua autoridade préconstituída. O relato se organiza em torno das crenças da alunaprofessora, trazidas de suas experiências anteriores ao estágio e 
posteriores a ele, bem como dos fatos, atitudes, pensamentos e ações que caracterizam o processo de negociação de valores, princípios e conhecimentos.

\section{COLETA DE DADOS E ANÁLISE}

Maria é uma dos 16 alunos do quarto e último ano do curso de Letras, cursando a disciplina de Prática de Ensino de Inglês-Estágio Supervisionado (doravante PEI), que participaram de nossa pesquisa. A investigação tinha por objetivo conhecer que crenças (ABELSON, 1979) os alunos do quarto ano do curso traziam, com que experiências elas estariam relacionadas e qual o impacto dos componentes socializadores e educacionais do curso de graduação na sua formação.

Os dados foram obtidos através de relato autobiográfico escrito no início do ano, inventário de crenças aplicado no começo e final de 1999, duas sessões de supervisão de estágio gravadas em áudio, um relatório de observação de aulas de inglês, e entrevista semiestruturada gravada em áudio, realizada no final do ano. Seguindo ERICKSON (1986), abordamos indutivamente os registros e identificamos temas para estudos mais aprofundados como este, e outros, como, por exemplo, sobre o entendimento dos alunos-professores quanto aos Parâmetros Curriculares Nacionais (GIMENEZ et al., 2000), a percepção dos alunos-professores quanto ao seu próprio desenvolvimento durante o estágio (MATEUS et al. 2000), reações dos alunosprofessores às suas experiências de aprendizagem de língua e metodologia de ensino de inglês na universidade (ORTENZI et al., 2000).

A busca de crenças nos registros foi feita tomando a definição de ABELSON (1979), segundo o qual os sistemas de crenças exibem as seguintes características:

1. presunção existencial: os sistemas de crenças geralmente contêm proposições a respeito da existência ou não-existência de entidades;

2. alternatividade: as crenças tratam de mundos alternativos que não foram necessariamente experienciados;

3. aspectos afetivos e avaliativos: as crenças se baseiam em sentimentos, emoções e avaliações subjetivas; 
4. armazenamento episódico: as crenças derivam seu poder subjetivo, autoridade e legitimidade de episódios ou eventos específicos;

5. não-consensualidade: os sistemas de crenças consistem de proposições que são reconhecidas como sendo não-consensuais;

6. desvinculação: os sistemas de crenças são tenuamente ligados e se relacionam com alguns eventos, situações e sistemas de conhecimento;

7. graus de certeza variados.

\section{A ALUNA-PROFESSORA}

Aos vinte e quatro anos de idade, Maria chega ao último ano do curso de Letras. Sua estória de estudante foi marcada por dificuldades externas à sala de aula, causadas por muitas mudanças de cidades durante sua infância, e, conseqüentemente, de escolas e por seu esforço individual para estudar, tendo que vencer quilômetros a pé para ir à escola e trabalhar em casa de uma familia. Maria só se recorda de uma única aula na escola pública em que, juntamente com colegas, fizera uma paródia de uma música e a apresentara à sala. Para ela, com aquela atividade a professora havia conseguido envolver toda a sala.

Dois episódios em sua vida marcam sua necessidade da língua inglesa: o vestibular e o contato com missionários religiosos americanos. Nas duas ocasiões, Maria recorreu àquilo que aprendera na escola pública, pela autodisciplina e gosto de traduzir e colecionar letras de música: vocabulário e estruturas da língua, sendo estas últimas por ela referidas como gramática e/ou ensino tradicional. Para ela, aquele conhecimento, que considera fruto de um ensino a que se refere inúmeras vezes como "defasado", deu-lhe acesso ao curso de graduação, uma vez que passou no exame vestibular, e também lhe possibilitou, com ajuda suplementar de mímica, estabelecer comunicação com falantes nativos de inglês durante alguns dias.

Ao chegar ao último ano do curso de Letras, a aluna já traz consigo experiência de três meses como professora de inglês em escola pública de uma cidade próxima. Nessa curta experiência, Maria parece ter "construído um conhecimento sobre o contexto 
escolar no qual o governo é omisso, os professores se sobrecarregam de turmas para sobreviver e negligenciam a qualidade do ensino, a escola não tem recursos materiais, e os alunos são desinteressados".

Uma extração das crenças de Maria $^{2}$, feitas a partir dos dados, mostradas a seguir, diz respeito a aspectos de sua biografia, pois estão todas relacionadas a suas experiências ou de aprendiz ou de professora de língua inglesa. O exame do conjunto de registros mostra que ela adentra o quarto ano de Letras já trazendo todas essas crenças, as quais resultam inalteradas ao final daquele ano. São elas:

1) O ensino na escola pública é fraco.

2) Saber língua é saber vocabulário e gramática.

3) A aprendizagem se dá através de tradução.

4) O uso de música promove aprendizagem.

5) $\mathrm{O}$ aluno aprende mais facilmente em ambiente descontraído.

6) É preciso gostar da língua para aprendê-la.

7) Ensinar leitura é difícil, trabalhoso.

Focalizamos a seguir como se deu a socialização de Maria na disciplina PEI. A negociação de seus conhecimentos, valores e princípios é vista no início, meio e final do quarto ano de seu curso ${ }^{3}$. A análise parte de suas próprias percepções e traz os fatos que marcaram essa experiência, suas atitudes, pensamentos e ações.

\section{CHOQUE DE CRENÇAS COM O CONHECIMENTO RECEBIDO}

O estágio curricular representa um período de conflito para Maria devido ao choque de sua visão de língua, ensino e aprendizagem com visões alternativas propostas no $4^{\circ}$ ano de seu curso na universidade. A orientação da supervisão de estágio coloca ênfase no ensino da leitura na escola pública, explorando gêneros textuais e estratégias de leitura; o tratamento dado à gramática se restringe a abordar os componentes lingüísticos relevantes para a compreensão do gênero textual em foco e sua função discursiva. As crenças de Maria, por sua vez, são formadas por sua percepção do que fora útil para sua 
aprendizagem de inglês em sua vida, bem como pela experiência, anterior ao estágio, de ensinar inglês em escola pública por três meses. Entre suas crenças, como mostramos, estão aquelas que priorizam o ensino de vocabulário e gramática por meio de tradução e o uso de música nas aulas.

Ao perceber a incongruência entre suas crenças e o conhecimento proposto na PEI [S1-L172-176] $]^{4}$, Maria assume uma atitude de abertura e franqueza com sua supervisora, revelando-lhe suas percepções com a intenção de evitar conflitos na supervisão [S1-L439-442]. Os excertos, cujos códigos de origem estão entre colchetes, seguirão cada asserção da análise, a título de ilustração, conforme abaixo:

...às vezes é muito incoerente o que a gente aprende aqui, e vai aplicar lá fora. Porque é, não existe estrutura, você vai trabalhar com texto, vamos procurar um texto dinâmico pra, já vem a questão: tem tempo pra procurar? Aí tá, procurou, achou um texto dez pra trabalhar como os alunos, a escola não fornece xerox ou está em matriz e não dá, eu tenho um cota limitadíssima, só dá pra prova. [Maria, S1-L172-176]

(...)

Eu coloquei assim porque não adianta levar, falar assim, ah, eu vou tentar levar, vou engolir e não falar né? [Hum, hum] Aí você não fala, daí que que acontece, você engole, daí fica aquela coisa chata, desagradável e que mesmo que seja útil pra mim eu acabo não usando porque foi uma experiência desagradável.[S1-L439-442]

Seu pensamento deixa transparecer rejeição ao conhecimento proposto, que vê como uma teoria que não se aplica na prática.

Então tem tudo isso, eu acho que, isso começa o problema tudo, é que muitas vezes você começa ver que țem muita teoria que não está se conciliando com a prática. Então é onde que você pensa assim pra que que eu vou saber de uma coisa que não vai assim, muitas vezes me ajudar nessa, nessa prática, a lidar pelo menos com essa prática. [S1-L300-303]

Sua ação resulta em planejamento de aulas fiel a suas crenças [S1-L328-330], o qual é questionado na supervisão. 


\section{CONFORMIDADE EXTERNA X RESISTÊNCIA INTERNA}

O questionamento da supervisora é interpretado por Maria como rejeição de seu conhecimento vivido [S2-L181-183]; a autopercepção sobre sua incapacidade de fornecer à supervisora argumentos para manter seu plano de aula em conformidade com suas crenças [S2L193-201] e sua necessidade de concluir o estágio levam a outro fato em sua socialização: a aquiescência estratégica [S2-L145-150].

Não, acho que com a discussão que nós tivemos, deu pra questionar algumas coisas, eu acreditei assim que pra mim, apesar de tudo foi muito útil, todos esses textos, mesmo que do modo tradicional, mas eu aprendi com eles, então de repente eu chego aqui, mas "porque?" "Ah, porque eu aprendi assim." "Mas por que?" (inc.) daí eu coloquei assim como o americano "Ah, mas não são todos que costumam lidar com isso", então parece que eu tento justificar o que eu aprendi e você vem com outro assim, que eu fico sem saber o que falar mesmo, por que pra mim realmente foi e é ainda uma regressão do que ficou e porque eu to ainda aqui na universidade, até que eu me dei bem com o Inglês, com a gramática até o $3^{\circ}$ ano porém com o vocabulário que a gente tinha, porque se fosse pra aprender aqui também, (inc.) então eu me preocupo no $1^{\mathcal{Q}}$ e $2^{\mathrm{e}}$ grau... [S2-L193-201]

(...)

É questão de você também, pra mim era tudo muito claro, pra mim você não iria concordar, então eu acho que não vale a pena comprar uma briga, eu to falando de um jeito, mas não tendo aceitação [S2-L181-183]

(...)

...daí não chegamos a ponto nenhum, tivemos a mesma discussão e daí eu peguei nesse ponto de que não adianta ficar puxando a corda de um lado, sendo que eu não vou conseguir levar pra esse lado, eu tenho que ir pro lado delas mesmo e a partir desse momento, aí sim peguei e falei "Vamos fazer o que você quer" até para parar discussões desagradáveis, então não é questão que uma aula, na outra aula eu falei "Vamos fazer o que você que" porque eu tenho seu contexto na minha cabeça de que como aconteceu a coisa, como você chegou a isso, ... [S2-L145-150]

Maria adota uma atitude de reserva nos encontros de supervisão, ocultando seus posicionamentos, preferindo calar-se [S2-L221-223]. 
Seu pensamento, entretanto, é expressão de sua resistência, de ceticismo em relação ao conhecimento recebido [S2-L34-49].

Professora-supervisora - Eu não discordo de você que não precisa ter vocabulário, não precisa aprender gramática.

M-A intenção que eu tive no começo, é que foi tudo realmente contra, e não adianta falar, porque se eu falo..., então vou ficar quieta. [S2-L221-223]

(...)

Professora-supervisora - O que tá escrito aqui, eu não to entendendo "Mesmo que eu não acredite integralmente nos resultados do aprendizado eficaz" aprendizagem eficaz pra mim, é qualquer aprendizagem que se realiza, qualquer aprendizagem que não seja eficaz, é não entendi isso.

$M$ - Então, deixa eu explicar isso.

Professora-supervisora - Hum.

M-Mas é questão de..., dessa estratégia que você apresentou que eu tive uma certa dificuldade, eu acredito que os objetivos dessa estratégia, é ter uma aprendizagem mais eficaz né, então esse se transforma em paralelo com a questão do tradicional, por exemplo, você pega lá e começa a questionar porque tanta gramática, será que vai ser necessário. [S2-L34-49]

A discordância interna de Maria, então oculta, se faz notar pelo apego às suas próprias experiências de aprendiz de língua inglesa [S-2-L216-220] e pelo desejo de reproduzi-las na escola pública, uma vez que considera os alunos de classe menos favorecida merecedores de tal benefício [S2-L256-261].

Então o que acontece, apesar dos pesares do ensino público lá, que vocês falam que tradução é isso e não sei o que lá, mas foi isso que me ajudou a me manter aqui, porque eu nunca fiz Inglês particular, e isso me faz acreditar que a aquisição do vocabulário, é bom, me dá retorno, é... produção dá retorno, gramática dá retorno, porque eu to vendo isso por experiência própria. [S2-L216-220]

(...)

Eu acho que porque eu preciso tá aqui pra fazer isso, por que que vai ser útil, o que que vai ajudar, talvez é até questão de meio social. Tem alunos que têm condição de pagar uma escola particular e tal, e eu nunca tive esse privilégio e meu irmão também não tem, então 
eu gostaria, o mínimo que fosse passado na rede pública pudesse ser aproveitado, então quando eu olho essa visão, não é olhando só simplesmente pra mim, mas é que menos favorecidos eles pudessem também ter um retorno. [S2-L256-261]

Entretanto, contrariando sua própria vontade, Maria assume que é preciso ceder à supervisão, fazendo o que sua supervisora quer [EF-L80-83] . Essa decisão e seus motivos são declarados à supervisora quando o número de aulas do estágio já havia sido cumprido [S2L164-171], revelando seu destemor ao recolocar sinceridade em sua atitude com a professora, isto é, ela nega o que aceitara antes.

Então foi onde que se tornou conflitantes e que chegou o momento em que eu pensei e falei até "vamos deixar de lado o que eu acredito". Não tava dando em nada, não ia direcionar nada, não iria levar nem a mim nem a ela a lugar nenhum. Eu precisava fazer o estágio, então foi onde que eu comecei a adotar a postura, o que é proposto. [EF-L80-83]

(...)

Professora-supervisora - Mas a minha percepção não é essa (incompreensível) a não ser essa de você achar que não quis, quer dizer, você colocou seu ponto de vista aqui na supervisão, mas não permitiu que eu visse a aula como você queria.

M- Hum, hum.

Professora-supervisora - Né, você falou "Não, vamos fazer a aula do jeito que ela quer" variado né, então tudo isso não tá aqui no papel né, aqui tá muito bonitinho, parece que não tem nenhum grande problema que a gente tá falando.

M - É, então é como eu falei pra você, eu fiz um relatório tudo. [S2L164-171]

\section{ENFIM, DE VOLTA ÀS CRENÇAS}

Em entrevista no final daquele ano, Maria mais uma vez exibe as crenças que entendera ser necessário esconder durante a fase de planejamento de aulas do estágio. Ela rejeita novamente o conhecimento proposto, com base na opinião expressada no início do ano de que o conhecimento recebido na universidade é teoria e, como tal, não se cumpre na prática [EF-L133-134;141-148]. 
Os PCNs [Parâmetros Curriculares Nacionais], a ideologia dele é muito linda, isso que é problema (risos). Eu leio aquilo, assim, eu não me conformo... [EF-L133-134] (...) É interessante (...) os PCNs quando eu leio, qualquer outra pessoa lê, você vai ver que a ideologia é linda, você vai trabalhar a partir da realidade do aluno, você vai ver o contexto social, você vai ver a questão de textos que sejam, que façam parte dessa realidade, não estejam assim tão fora da realidade (...) Então, você vê que é uma coisa que parece muito boa, mas quando você chega na prática, parece que existe uma incoerência... [EF-L141-148]

Maria conserva suas antigas crenças de que é preciso saber vocabulário, gramática [EF-L72-80] e de que a música proporciona aprendizagem. Essa crença, trazida da estória de aprendiz de inglês, acaba ainda mais fortalecida pela oportunidade que conseguiu criar para inseri-la em uma aula do estágio curricular. Ela usa o depoimento de apreciação, aceitação e valorização dos alunos para suporte à sua percepção da validade de sua escolha [EF-L183-191].

...eu queria que os alunos aprendessem também a gramática, aprendessem também através da tradução como eu aprendi e é claro diversificando, levando alguma coisa diferente, mas que eles aprendessem isso, e foi assim contra a postura da supervisão, até baseada nos PCNs em que você vai trabalhar a gramática só pertinente ao texto. Então não tinha mais aquela questão de você trabalhar todos os tipos de pronomes; é só o que tá ali. Então, aquilo começou a ser conflitante para mim porque eu comecei a ver que os alunos iriam ter uma defasagem, ao meu ver. Parecia que ia ficar assim como um vácuo porque vai aprender uma parte, só aquilo, mas tem outros tipos de pronomes, por exemplo, né. [EF-L72-80] (..)

...porque eu defendo a gramática, né, a gramática fazer método tradicional, né, então foi tudo aquilo que eu aprendi não foi em vão, então é, quando eu vi que de repente estivesse deixando de lado essa gramática, é como se estivesse privando os alunos, principalmente os de baixa renda, de aprender alguma coisa de fato, não que seja devido à gramática, mas, embora algumas pessoas sejam contra, você vai ver assim que dentro, você vai escrever uma carta, você vai precisar da gramática, você vai ler alguma coisa, tem alguma coisa, você vê que a gramática tá ali. [EF-L183-191] 


\section{LIÇÕES DO ESTUDO DE CASO}

Nosso trabalho, enquanto formadoras de professores de língua inglesa, defende abertamente o ensino da leitura na prática do futuro professor (REIS, 2000). Paralelamente à apresentação e discussão de visões de leitura, ao ensino de técnicas para implementar a concepção que propomos aos alunos-professores, objetivamos o desenvolvimento de sua reflexão sobre a própria prática. Para isso, incentivamos a escrita de diários durante o estágio e incluímos como item de avaliação a escrita de reflexões a respeito de uma questão surgida na prática (GIMENEZ, 1998).

Nos encontros de supervisão, lidamos com alunos-professores que afirmam não terem a menor idéia de onde começar em seu planejamento de aulas, com os que pouco verbalizam o que pensam sobre sua prática em sala de aula. Diante desses alunos, indagamo-nos sobre como promover sua autonomia. Outras vezes, temos diante de nós alunos-professores com um conhecimento sobre ensinar previamente constituído, aparentemente impermeável a qualquer outro. A pesquisa da qual se originou o presente estudo de caso mostra ambos perfis, sendo o relato sobre a socialização de Maria uma ilustração do último. O uso da aquiescência estratégica foi a saída que ela encontrou para terminar seu estágio. Embora tendo adaptado seu comportamento à situação, seus valores foram mantidos intocados, traduzindo, ao final de seu último ano de curso, a seguinte percepção: O ensino público é pobre; porém, aprendi com ele e como aprendi vou ensinar. Está claro que, apesar de possivelmente motivada pela autoridade pré-constituída de supervisores, a aquiescência estratégica da aluna-professora coloca em xeque nossa concepção de formação de professores e pode representar a nulidade de nossos esforços. Entendemos que não se trata de como se exerce a autoridade de supervisores, mas o que devemos fazer para alcançar sucesso em nossos objetivos. Estamos cientes, também, que a aquiescência estratégica não pode ser rotulada como indesejável em qualquer situação, pois como supervisoras de estágio também testemunhamos casos em que o aluno-professor abandona totalmente a orientação 
recebida na supervisão, amolda-se às expectativas da escola, que, não raro, passa ao futuro professor uma visão de que o que propomos é utópico; que nada é possível fazer; que não adianta sequer tentar. A explicação fornecida pelo aluno-professor para amoldar-se às expectativas da escola é não criar atritos na escola, poder cumprir as formalidades de um estágio conforme colocadas pela direção daquela instituição. Em outras palavras, a aquiescência estratégica pode também ser necessária para que, um dia, o conhecimento proposto na universidade seja resgatado na sala de aula.

Ainda que o resultado deste estudo possa ser frustrante para nós, ele nos ajuda a conhecer uma das raízes de uma socialização marcada pela conformidade externa a princípios, valores e conhecimento, simultaneamente à resistência e discordância internas. Vemos na biografia de um indivíduo que uma experiência prática de ser professor, antecedendo seu estágio curricular, tem força o bastante para guiar suas ações desde o planejamento de aulas.

O caso de Maria mostra que três meses ensinando inglês parecem ter sido suficientes para assimilar um discurso que divide com o governo a responsabilidade pela reprodução de um ensino por ela referido repetidamente como deficiente, fraco. No mesmo período viu-se a implementação de práticas baseadas em suas crenças. Isso tudo nos ensina sobre a necessidade de repensar os meios que utilizamos para atingir nossos objetivos. Uma possibilidade é inserir experiências concretas durante o estágio, através das quais o aluno-professor possa acrescentar a sua biografia uma nova estória de aprendiz da língua a ser ensinada. Quem sabe, esse tipo de iniciativa possa ser uma base de referência para aqueles cujas crenças ainda não se cristalizaram. 


\section{NOTAS}

${ }^{1}$ Nome fictício.

${ }^{2}$ No anexo I, estão as crenças da aluna-professora, juntamente com a indicação dos tipos de registros em que foram identificadas.

${ }^{3} \mathrm{O}$ anexo II sintetiza a análise em torno dos fatos, atitudes, pensamentos e ações de Maria no começo, meio e final de 1999.

${ }^{4}$ Referência à origem dos dados, sendo S1, sessão de supervisão 1 , gravada em 17/03/1999, L, linha, 172-176, a respectiva numeração de linhas.

${ }^{5}$ Referência à origem dos dados, sendo EF, entrevista final, gravada em 18/11/1999, $\mathrm{L}$, linha, 80-83 a respectiva numeração de linhas.

${ }^{6}$ Inventário aplicado no início do ano de 1999.

7 Inventário aplicado em dezembro de 1999.

${ }^{8}$ A-32 refere-se à asserção de número 32 do inventário de crenças.

9 ROA significa relatório de observação de aulas.

\section{REFERÊNCIAS BIBLIOGRÁFICAS}

ABELSON, R. Differences between belief systems and knowledge systems. Cognitive Science 3, p.355-366, 1979.

ERICKSON, F. Qualitative methods in research on teaching. In: WITTROCK, $M$. C. (Ed.) Handbook of research on teaching. New York: Macmillan Publishing Company, 1986. p.119-161.

GIMENEZ, T. N. Caminhos e descaminhos: a pesquisa na formação de professores de língua estrangeira. The Especialist, São Paulo, v.19, n.2, p.257-271, 1998. et al. Conbecimento e práticas pedagógicas: interpretaçôes dos PCNs. Londrina, 2000. (Mimeogr.)

MATEUS, E.F. et al. O processo de desenvolvimento durante a Prática do Ensino de Inglês, segundo os próprios alunos-professores. Londrina: 2000. (Mimeogr.)

ORTENZI, D.I.B.G. et al. Reações dos alunos-professores às suas experiências de aprendizagem de lingua e Metodologia de Ensino de Inglês na universidade. Londrina, 2000. (Mimeogr.)

REIS, S. Globalization and Education: the contribution of language teacher educators. Braz-Tesol Newsletter. São Paulo, mar., p.10-12, 2000.

STATON, A. Q., HUNT, S. L. Teacher socialization: review and conceptualization. Communication Education, v.41, p.109-137, 1992.

ZEICHNER, K., TABACHNICK, B.R. The development of teacher perspectives: social strategies and institutional control in the socialization of beginning teachers. Journal of Education for Teaching, n.11, p.1-25, 1985. 
ANEXO I: Crenças sobre ensino/aprendizagem de inglês reveladas na $\mathrm{PEI}$

\begin{tabular}{|c|c|c|c|c|c|c|c|}
\hline Crença & $\begin{array}{l}\text { Inven- } \\
\text { tário } \\
\text { inicial }\end{array}$ & $\begin{array}{l}\text { Autobio- } \\
\text { grafia }\end{array}$ & $\begin{array}{l}\text { Relatório } \\
\text { Obser- } \\
\text { vação }\end{array}$ & $\begin{array}{l}\text { Super- } \\
\text { visão } \\
25 / 3 / 99\end{array}$ & $\begin{array}{l}\text { Super- } \\
\text { visão } \\
17 / 8 / 99\end{array}$ & $\begin{array}{l}\text { Entre- } \\
\text { vista }\end{array}$ & $\begin{array}{l}\text { Inven- } \\
\text { tário } \\
\text { final }\end{array}$ \\
\hline $\begin{array}{l}\text { 1. O ensino na } \\
\text { escola pública } \\
\text { é fraco }\end{array}$ & $\begin{array}{l}\mathrm{A}-32^{\mathrm{B}} \\
\mathrm{A}-42\end{array}$ & p. 2 & & $\begin{array}{l}\text { [S1-L67-69; } \\
\text { 101-102; } \\
\text { 136-137; } \\
178 ; 181 ; \\
289-291]\end{array}$ & 213-215; & & $\begin{array}{l}\text { A-32 } \\
\text { A-42 }\end{array}$ \\
\hline $\begin{array}{l}\text { 2. Saber língua } \\
\text { é saber } \\
\text { vocabulário }\end{array}$ & A54 & p. $2 ; 3$ & & $\begin{array}{l}\text { [S1-L101- } \\
\text { 102;] }\end{array}$ & $\begin{array}{l}\text { [S2-L7-8; } \\
34-35 ; \\
114-115 ; \\
177-178 ; \\
216-219 ;\end{array}$ & $\begin{array}{l}\text { [EF-L14-17 } \\
25-28 ; \\
32-34 ; \\
61-62 ; \\
83-86 ; \text { ] }\end{array}$ & A54 \\
\hline $\begin{array}{l}\text { 3. Saber língua } \\
\text { é saber } \\
\text { gramática }\end{array}$ & & p. $2 ; 3 ; 4$ & & $\begin{array}{l}\text { [S1-L21-22; } \\
84-83 ; \\
101-102 ; \\
332-334 ; \\
389-393]\end{array}$ & $\begin{array}{l}\text { [S2-L194- } \\
196 ; 219 ;]\end{array}$ & $\begin{array}{l}\text { [EF-33-34; } \\
72-73 ; \\
169-172 ; \\
183-191 ;]\end{array}$ & \\
\hline $\begin{array}{l}\text { 4. Aprendizagem } \\
\text { se dá através } \\
\text { da tradução }\end{array}$ & A29 & p. 4 & $\begin{array}{l}\text { [ROA-L21- } \\
23]^{9}\end{array}$ & $\begin{array}{l}\text { [S1-L21-22; } \\
\text { 101-102] }\end{array}$ & [S2-L34-35] & [EF-L72-73] & A29 \\
\hline $\begin{array}{l}\text { 5. O uso de } \\
\text { música } \\
\text { promove a } \\
\text { aprendizagem }\end{array}$ & & p. $2 ; 4$ & & $\begin{array}{l}\text { [S1-L99-100 } \\
\text { 189-192; } \\
202-209 ; \\
389-392]\end{array}$ & & $\begin{array}{l}\text { IEF-59-64; } \\
257-263]\end{array}$ & \\
\hline $\begin{array}{l}6.0 \text { aluno } \\
\text { aprende mais } \\
\text { facilmente em } \\
\text { ambiente } \\
\text { descontraído }\end{array}$ & A- 51 & & & $\begin{array}{l}\text { [S1-L189- } \\
\text { 192] }\end{array}$ & & $\begin{array}{l}\text { [EF-L59- } \\
67]\end{array}$ & A-51 \\
\hline $\begin{array}{l}\text { 7. É preciso } \\
\text { gostar da } \\
\text { língua para } \\
\text { aprendê-la }\end{array}$ & $\begin{array}{l}\text { A44 } \\
\text { PA-C }\end{array}$ & p. $2 ; 3$ & & $\begin{array}{l}\text { [S1-L38-43; } \\
\text { 99-100; } \\
332-333]\end{array}$ & & $\begin{array}{l}\text { [EF-L64- } \\
67]\end{array}$ & $\begin{array}{l}\text { A44; } \\
\text { PA-c }\end{array}$ \\
\hline $\begin{array}{l}\text { 8. Ensinar } \\
\text { leitura é dificil, } \\
\text { trabalhoso }\end{array}$ & & & & $\begin{array}{l}\text { [S1-L173- } \\
176]\end{array}$ & $\begin{array}{l}\text { [S2-L134- } \\
\text { 139] }\end{array}$ & $\begin{array}{l}\text { [EF-L152- } \\
158]\end{array}$ & \\
\hline
\end{tabular}




\section{ANEXO II: Fatos, atitudes, pensamentos e ações na socialização de Maria na PEI}

\begin{tabular}{|c|c|c|c|}
\hline & \multicolumn{3}{|c|}{1999} \\
\hline & Marso & Agosto & Noveinbro \\
\hline Fatos & Choque de suas crenças & $\begin{array}{l}\text { Aquiescência estratégica } \\
\text { com o conhecimento } \\
\text { recebido na PEI }\end{array}$ & Retorno às crenças \\
\hline Atitudes & Abertura, franqueza & Reserva & Abertura, franqueza \\
\hline Pensamentos & $\begin{array}{l}\text { Rejeição } \\
\text { - Opinião de que o } \\
\text { conhecimento proposto } \\
\text { é uma teoria que não se } \\
\text { aplica na prática. }\end{array}$ & $\begin{array}{l}\text { Resistência } \\
\text { - Ceticismo em relação } \\
\text { ao conhecimento } \\
\text { proposto; } \\
\text { - Apego às próprias } \\
\text { experiências de } \\
\text { aprendiz de língua } \\
\text { inglesa; } \\
\text { - Desejo de reproduzir } \\
\text { na escola pública sua } \\
\text { experiência de aprendiq } \\
\text { naquele contexto. }\end{array}$ & $\begin{array}{l}\text { Rejeição do proposto } \\
\text { - Manutenção } \\
\text { das crenças } \\
\text { originais; } \\
\text { - Visão de que o } \\
\text { conhecimento } \\
\text { proposto no } \\
\text { curso é teoria } \\
\text { e como tal não se } \\
\text { cumpre na prática; } \\
\text { Valorização da } \\
\text { crençá de que } \\
\text { alunos aprendem } \\
\text { com música, } \\
\text { através de } \\
\text { experiência } \\
\text { no estágio. }\end{array}$ \\
\hline Açoes & $\begin{array}{l}\text { Resistência } \\
\text { - Planejamento de aula } \\
\text { conforme suas } \\
\text { próprias crenças; } \\
\text { Desabafo com a } \\
\text { supervisora sobre o } \\
\text { choque de suas crenças } \\
\text { com o conhecimento } \\
\text { proposto, a fim de evitar } \\
\text { um relacionamento } \\
\text { tenso durante a } \\
\text { supervisão. }\end{array}$ & $\begin{array}{l}\text { Aquiescência estratégica } \\
\text { - Planejamento de aula } \\
\text { conforme expectativas } \\
\text { da supervisora; } \\
\text { - Revelação à professora } \\
\text { sobre sua percepção } \\
\text { de como são diferentes } \\
\text { seus princípios relacio- } \\
\text { nados a ensino/ } \\
\text { aprendizagem; } \\
\text { - Declaração à super- } \\
\text { visora sobre suaa } \\
\text { desistência de resistir } \\
\text { à orientação recebida. }\end{array}$ & 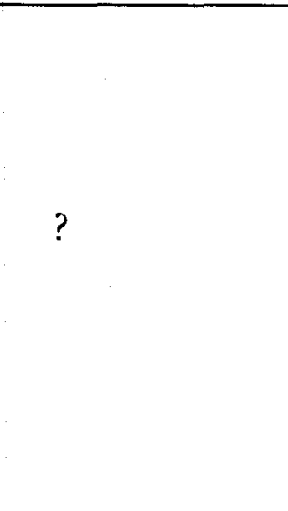 \\
\hline
\end{tabular}

